\title{
Conducting Online Speaking Class: Adjustment and Compensation
}

\author{
Agustina Lestary ${ }^{1 *}$ \\ ${ }^{1}$ STKIP PGRI Banjarmasin \\ *Corresponding author.Email: agustinalestary@stkip.ac.id
}

\begin{abstract}
Since early 2020, every educational institution has been forced to make major changes in the teaching-learning process. What was once an occasional practice, online learning, now becomes the only option available to transfer the knowledge from the teachers to the students. Everyone tries to adapt to the current situation, and some struggled, while others can make smooth changes from face-to-face learning to online learning. By employing a narrative approach, this study describes how a speaking class is conducted through online learning. A lecturer of the English Language Education Study Program of STKIP PGRI Banjarmasin revisits the speaking class she completed, including the activities assigned to the students, platforms used, and assessment. The paper also discussed the compensation need to be made during the 16-meeting class due to the shifting of the platform from offline to the online classroom. The result of the study will serve as a reflection towards the speaking class and provide insight to other lecturers in preparing their speaking classroom.
\end{abstract}

Keywords: teaching speaking, online learning, critical thinking

\section{INTRODUCTION}

Online classroom and online learning have been introduced by many teachers and experts way before the Covid-19 pandemic broke in 2020. It offers learning flexibility for the students and an infinite source of material and exercises for both teachers and students. Distance is also no longer an issue when it comes to online teaching-learning. However, some teachers are reluctant to do full online teaching for various reasons, from technology resistance to more philosophical reasons that online teaching misses the very essence of teaching itself. Yet, some teachers opt for hybrid learning - combining the infinite source from online and the classical connection on face-to-face classrooms,

Nevertheless, the pandemic hit the world hard, not only the health sector but also the educational sector. The shift of the teaching-learning process from the traditional to the online classroom is inevitable - rushed even. Teachers and students are forced to adapt to the 'new normal,' heavily relying on access to the internet and making the most use of the online platforms available.
Research about the utilization of online platforms for EFL teaching and learning during the pandemic is flourishing, providing information and insight for teachers who are still struggling with their classrooms.

Teaching speaking skills in the era of online learning, on the other hand, could be very problematic. Many teachers might find it challenging because speaking is a productive skill. Online learning should help students practice their speaking skills, boost their confidence, lift their motivation, and enable them to experience twoway interaction in an online circumstance. It is surely hard work for the teachers.

This study is conducted to answer the question of "how does the teacher adjust the teaching-learning process of speaking skills in online learning to compensate for the lack of face-to-face connection?" It is hoped that the result of this study could be used as a reference for teachers to conduct their class, especially speaking class. 


\section{LITERATURE REVIEW}

Some studies had proposed the implementation of online learning or hybrid learning even before the pandemic broke. A study, for example, combined video conferencing and face-to-face learning to teach speaking skills. This blended learning could improve the students' speaking skills and receive a positive response from the students. [1] Further, Mounika and Thamaran [2] also mentioned a wide array of resources available online that could be used by the teachers and the students for learning English.

Nevertheless, just like any other learning system, many challenges should be faced by teachers and students [3] [4]. The first issue is the platform that teachers can use, whether it should be synchronous or asynchronous and whether it can accommodate unlimited users or a certain number. The second issue is the pedagogy. Ideal online learning should allow students to learn just as much as they would learn through face-to-face learning - and more if it is possible. Adjusting the material and resources to learn and reach the objectives that the course has set is also a challenge for the teachers. The third issue is the teachers' development which is closely related to the teachers' digital literacy. Many teachers are still struggling with using online resources and platforms, blending their usual conventional teaching and the online learning system.

Regarding teaching English speaking skills, ThiTuyetAnh [5] mentioned some factors that the teachers should be aware of. The first factor, teachers should allow the students to talk a lot, and it will be related to the second factor of a good speaking class, which is ensuring that the students are given the chance of talking fairly. The third factor is the teachers could boost students' motivation and confidence in speaking English. The fourth factor is the students can enjoy the interactive learning in the speaking class. Therefore, it is essential to transfer these factors to online learning. Further, assessment in speaking class should cover the students' grammar, vocabulary, comprehension, fluency, pronunciation, and task fulfillment [6]. In line with this theory, Luoma [7] emphasized that in developing speaking assessment one should know the focus of the speaking skill being assessed, the rating criteria, as well as the way assessment conducted.

Even though speaking is regarded as a productive skill and preferably should be taught through two-way communication, conducting a speaking classroom online is still more than possible. Luoma [7] explained that there are five key components that teachers should be paying attention to in teaching speaking online. The first is language awareness promotion. The second is vocabulary and language pattern development. The third is language pattern development. The fourth and fifth are lesson delivery and cooperative and collaborative learning. Further, assessment points should also be carefully designed to measure the students' knowledge and abilities after doing a course online.

\section{RESEARCH METHOD}

This study employed narrative inquiry. The researcher revisited her Academic Speaking class and described the activities conducted during the whole course. Academic Speaking is the last course of the Speaking series at the English Language Education Study Program of STKIP PGRI Banjarmasin. The course was conducted in 16 meetings, including the middle and final term tests. This course aims to promote students' critical thinking and develop students' speaking skills in an academic setting such as debate and presentation. Eighteen students were attending the class. Due to the pandemic, the class was still conducted online with an asynchronous and asynchronous learning system.

\section{RESULTS AND DISCUSSION}

As mentioned in some studies, there are some challenges and drawbacks experienced by both teachers and students as the classroom shifts from a conventional face-to-face classroom to the online one [3, 4]. Provided that there is a lack of face-to-face engagement, the teacher might find it quite challenging to motivate the students, set the learning pace, and assess the students. On the other hand, the students might find it more difficult to understand the material, instructions, and feedback as they are mostly given in the written form. There were little to no opportunities for clarification and confirmation. On top of that, online classroom relies heavily on the internet connection, which poses another problem for students and teachers, especially for those in remote areas and underprivileged. Further, there are two major problems faced by the teacher in this study in conducting speaking classroom through online learning; platform and pedagogy

\subsection{Issues of Platform}

Despite the wide array of platforms available for online learning, from video conferences to quizzes, the teacher pointed out two struggles in finding the right platforms for the speaking classroom. The first struggle is the features of every platform are unique and different from one to another. The teacher mentioned that learning every online resource out there was timeconsuming and tiring. The teacher did not only need to know the way to use these resources but also how to 
utilize these platforms to achieve the learning objectives in the classroom. Often, she had to create two accounts to try the features as a teacher and get a glimpse of the students' experience in using the platform. In addition, she had to find the same platform that could help her teach speaking and mimic the learning situation of that face-to-face classroom.

The second struggle is the additional expenses. Even the most used platforms such as zoom meeting charge the users for access to unlimited features. Those who use the free account will be constrained by time limitations and very basic meeting features. The teacher explained that many platforms charged the users for exclusive features, and it could be very frustrating for the teacher since the institution provided no additional budget. The most used google classroom platform could only offer so little when it came to speaking classrooms. Since video and audio recording were the most common activities in speaking classrooms, the platforms used for teaching speaking skills should provide access to video and audio recording and huge cloud storage. Unfortunately, very few online platforms offer these two features for free.

\subsection{Issues of Pedagogy}

The issues of pedagogy refer to the challenges the teacher faces in transferring the knowledge in the online classroom. The teacher identified three main issues in teaching speaking skills through online learning; course objectives, material delivery, and assessment. The time restriction and internet connection mostly caused the problems. Contrary to what many people said that an online classroom provides time flexibility for the students to learn and break the four wall boundaries of the traditional classroom, the teacher found it quite difficult to squeeze the material delivery, discussion, and reinforcement activities within the allotted time. In addition, the teacher explained that she had to consider the fact that the students were also required to attend other classes and did another assignment from other lecturers.

The first issue pointed out by the teacher is course objectives. The main objectives of the Academic Speaking class, as stated by the course syllabus, are (1) the students can demonstrate good critical thinking in delivering their opinion, (2) the students can host a formal event (as emcee and moderator), deliver welcoming speech, and do the academic presentation, (3) the students can do a debate. The teacher realized that the allotted time of 14 meetings with 90 minutes for every meeting would not be enough to cover the whole material that the students should learn. Furthermore, interruption during the meeting due to the poor internet connection or other technical problems was expected to happen, resulting in reduced learning time. In addition, the teacher also said that the students' responding time was longer in the online classroom than during the faceto-face learning process.

The second issue explained by the teacher is the material delivery. Still related to the time restriction and poor internet connection, the teacher should organize the material delivery carefully so that it would not take too much time and there was enough time for discussion and practice. Further, she mentioned that the material should be concise so the students could understand it easily without taking too much time. It was a challenge itself since some material was quite complicated such as about debate system.

The third issue is the assessment. Assessment is integral to the teaching-learning process. It facilitates students to learn and improve instruction and take a variety of types. When it comes to the assessment, the teacher mentioned that the main problem did not lie in the students' competence evaluated or the speaking rubrics but the minimum standard of the evaluation. Due to the current situation where the interaction between teacher and students was limited, direct feedback was not always given, and material delivery and learning objectives were compromised. Therefore, it was only natural that the teacher should lower the marking benchmark for the students.

As the issues of platforms and pedagogy are interrelated, the teacher explained how she negotiated these two major challenges when teaching speaking on online platforms. The teacher admitted that translating the objectives of speaking class in the online classroom was challenging yet still possible. Negotiation and compensation were inevitable, but the goal was still the same - providing the best learning experience for the students. On the ground that the 14-meetings of the online classroom could not cover the whole objectives of the Academic Speaking class, the teacher compromised the objectives into (1) critical thinking, (2) speech, (3) host a formal event (as emcee and moderator) and academic presentation.

Three online platforms were used to achieve these course's goals. The main platform was a moodle-type of Learning Management System (LMS). The LMS was introduced by the institution and could be accessed by the teachers and the students. Material and assignments were mostly posted in this LMS. The teacher stated that the LMS was simple and quite easy to operate. For example, the teacher could post a video without worrying it would take up the google drive storage like the google classroom. There was also no storage limit, and it was free, unlike many other platforms. In addition, the students could also do audio recording and 
submitted it directly without the need to record their audio on their phone and uploaded it later.

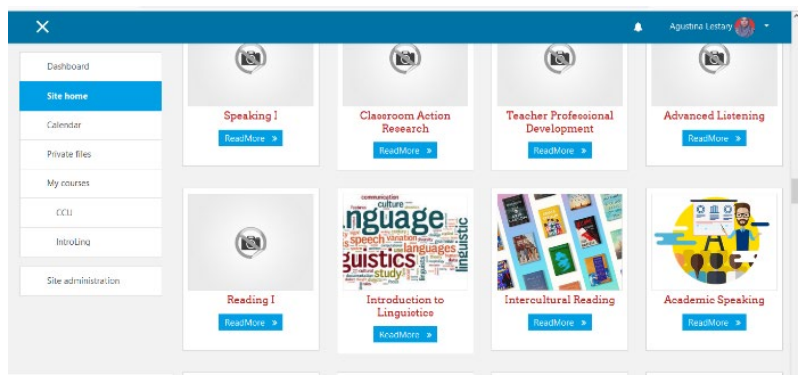

Picture 1. LMS interface

Another platform used was google meeting to host the online meeting. Unlike zoom, there was no 40minute time limit in google meetings, allowing the teacher to conduct the class in 90 minutes. However, the teacher noted some technical problems when using google meetings, such as the students could just be kicked out of the room even with the stable internet connection, and there were no breakout rooms. Yet, it was still a better option than zoom as it was free. Since google meetings required big data, the teacher usually invited the students to the online rooms for a short discussion and some students' presentations.

The last platform used by the teacher was Anchor - a platform for the broadcasting podcast. The students were required to record a podcast every two weeks. It was done to allow students to practice their speaking without the presence of a visible audience. By doing so, it is hoped that the students would be less anxious since no one was paying attention to them when they were speaking, and they could have more preparation before doing the recordings. The students might share the link to their podcast with their friends if they wanted to, but it was not an obligation. The Anchor was chosen since it was easy to operate and free. The recordings could also be accessed through many online platforms such as Spotify and Itunes. Youtube was also used sometimes, but it was only referred to as a source of the materials. The teacher herself never created youtube content.

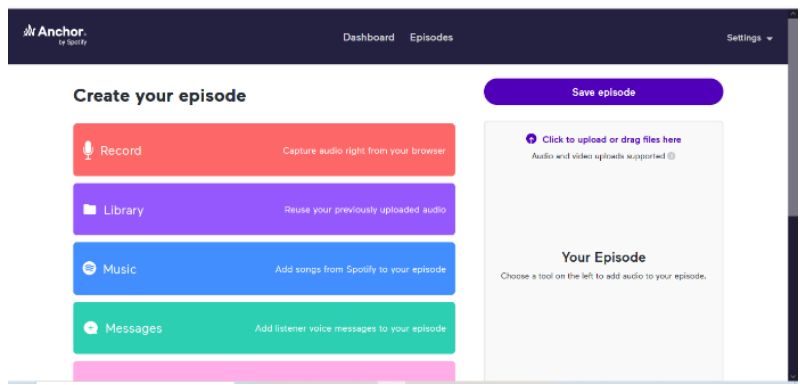

Picture 2. Anchor interface

Further, the teacher also described how the class was conducted and the assignments given to achieve the course objectives - the teacher assigned some recording tasks in the first five meetings to help the students with their critical thinking. The project could be accessed in the LMS. Some pictures and videos were given, and the students were required to provide opinions about what they saw. Some guided questions were given to help the students structuring their speech. The pictures or videos posted were debatable issues such as working mothers, homemakers, or online learning. It is in line with [8], who mentioned that media such as pictures could stimulate the students' critical thinking process.

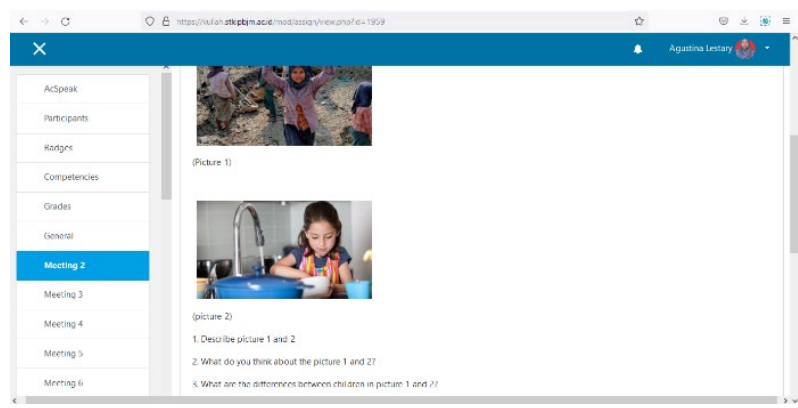

Picture 3. Pictures and guided questions

During the first five meetings, the students were also grouped into five different groups. Each group should attend one online meeting via google meet. The online meeting was deemed important so that the students could practice their speaking in such two-way conversations. Still, the students were required to attend one of the five scheduled meetings under the consideration of cutting their data internet expenses. Those groups who were not following the online meeting should do their recording assignment.

To achieve the second course objective of 'delivering a speech,' the teacher decided to do flip learning to learn about the material beforehand. The teacher posted a video clip from youtube as a reference and required the students to identify the structure of the speech based on material about speech's structure. The video chosen was a speech from a Korean boyband, Bangtan Boys (BTS), at a United Nations General Assembly in 2018. 


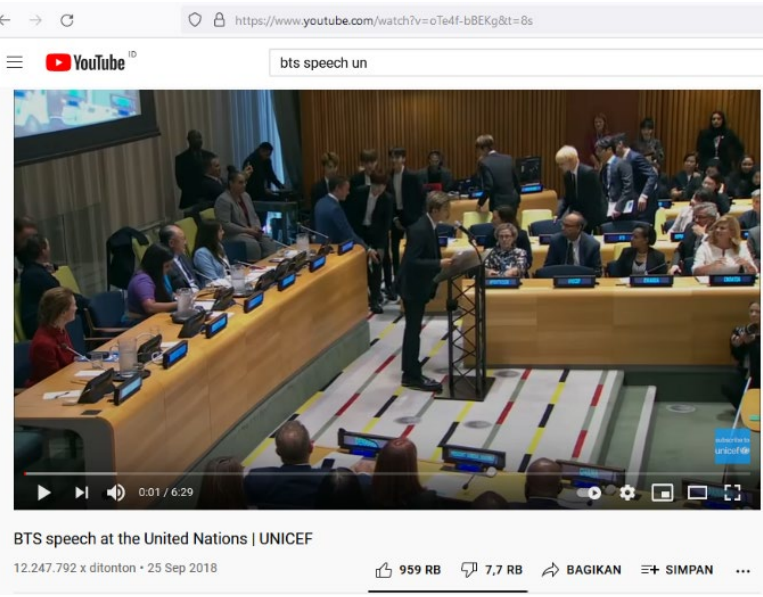

Picture 3. Material from youtube

The video was chosen to pique the students' interest as the boyband was quite popular among teenagers nowadays, and the topic of bullying and dream was close to the students. Therefore, in the next meeting, the teacher discussed the video and the material with the students. By providing the material before the online meeting, the teacher expected that the meeting would only focus on discussions and answering questions from the students so that the meeting could be finished within the allotted time.

Google meeting was used more often in the second half of the semester. It was quite inevitable since the material required a lecture and presentation. The course was directed to help the students learn how to host an academic event - be it as the emcee, the moderator, or event the speaker, and help the students understand other opinions and deliver their stand. At the $9^{\text {th }}$ meeting, all students were required to attend the online classroom to learn the job description of the emcee and moderator. The students attended an online seminar ahead beforehand, and they have given the assignment of identifying what the emcee and moderator should do. It helped the teacher explain the material related to being emcee and moderator, which could reduce the meeting time.

The class, then divided into eight groups, of which two groups would hold their event on the next four meetings. There were other online meetings but only two groups of students logged in every meeting. The meetings were organized not to need to spend a lot on the data internet connection. To push further on how students could demonstrate their critical thinking, the teacher provided the students with some video of the interview from youtube and asked the students to deliver their opinion regarding the issues discussed in the interview and the respondents' answers. At the last meeting, the teacher assigned the students to conduct a similar interview with their preferences and reported the interview result in a short video along with their stands.

To cater to the students' needs to practice their speaking, the teacher also required them to do podcasts every two weeks. The online application of Anchor was used since it was easy to use and it was connected to other online music applications, such as iTunes and Spotify. The teacher hoped that the students could be more confident in speaking and feel less anxious by doing this activity. [9] [10] stated that the absence of a visible audience could help the students speak English. It is also in line with the result of the study by Ningias and Indriani [12] who mentioned that the students showed positive self-efficacy and felt confident during online learning.

In terms of assessment, the teacher needed to lower the bar considering that the students had limited speaking experience, and feedback was not always given. Expecting the students to achieve the 'prepandemic learning outcomes' would be very unfair to the students since the teacher made some adjustments to the teaching-learning process here and there. The assessment still measured the students' speaking competence, such as fluency, pronunciation, lexical resources, and grammar, yet the minimum standard was lowered.

The assessment conducted in this course could be categorized as technology-based task. As it has been explained by Ningias and Indriani [12] that in technology-based task, the instructions are given by the teachers and the tasks are submitted by the students through online technology. Yet, the assessment is still given manually by the teachers. Due to the nature of the course during the pandemic situation, the assessment was conducted through online technology. Instructions were given at LMS or during video conference and the tasks should be submitted at the LMS.

Table 1. Speaking rubric adapted from Rahmawati \& Ertin (2014)

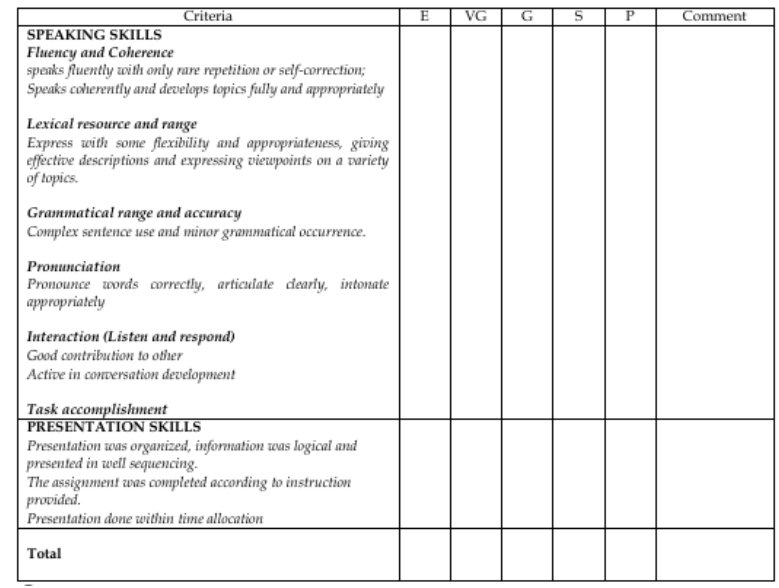


The following is the rating point used for the last Academic Speaking class

Table 2. Rating point

\begin{tabular}{|l|c|l|}
\hline Initial & Criteria & Score \\
\hline E & Excellent & $90-100$ \\
\hline VG & good & $80-89$ \\
\hline G & Good & $70-79$ \\
\hline S & Satisfactory & $60-69$ \\
\hline P & poor & $40-59$ \\
\hline
\end{tabular}

The teacher did not always stick to the rubric in assessing students' assignments as it has been mentioned by Luoma [7] that assessment may reflect what the developers' belief- in this case is the assessor or the teacher. The teacher would give additional points for those who religiously submitted every work. As a result, the students who could stretch their recording to meet the time limit would also be regarded as fluent despite stuttering or repetitive words.

\section{CONCLUSION}

The shifting from the traditional face-to-face classroom to online learning is inevitable - the pandemic only rushed this change. There will always be issues when it comes to teaching, be it within the classroom wall or wall of the internet. Before deciding how to approach the online classroom, the teachers should formulate the objectives carefully. They need to be realistic and feasible. Simplifying the objectives is normal.

Further, choosing the platforms and online resources to use is not an easy feat as well. Many things should be considered, such as the students' access to the internet and the platforms' features. There are great platforms available, but not all of them will fit the class and what the students really need. Last but not least, the teachers should also design assessments that include the objectives and the situation of their class. Modifying the rubric and minimum evaluation standard is not a sin since the current online teaching and learning process is not ideal. There are still some negotiations and adjustments needed to be made.

\section{REFERENCES}

[1] M. Syaifudin, Improving Students Speaking Skill by Implementing Blended Learning (Online learning and Classrom), in: Proceedings of Jurnal INFORMA Politeknik Indonesia Surakarta Vol 3, 2017.

[2] K. Mounika and S. Thamarana, Teaching Speaking Skills Online: Prospects and Possibilities, in Proceedings of ELTAI TIRUPATI CHAPTER 6th Annual International Conference, Tirupathi, 2018.

[3] C. M. Tschida, E. M. Hodge and S. W. Schmidt, Learning to Teach Online: Negotiating Issues of Platform, Pedagogy, and Professional Development, in Handbook of Research on Learning Outcomes and Opportunities in the Digital Age, Hershey PA, USA, Information Science Refeence, 2016, pp. 664-684.

[4] P. Ramadhani, The Teaching Procedures for Online Public Speaking Class, in: Proceedings of Journal of Linguistics, English Teaching and Education, vol 1, 2020, pp. 79-81.

[5] N. ThiTuyetAnh, The Key Principles for Development of Speaking, in: Proceedings of International Journal on Studies in English Language vol 3, 2015, pp. 49-53.

[6] Y. Rahmawati and Ertin, Developing Assessment for Speaking, in: Proceedings of IJEE, vol 1, 2014, pp. 199-210.

[7] S. Luoma, Assessing Speaking, Cambridge, UK, Cambridge University Press, 2004.

[8] A. Sritulanon, P. Chaturongakul and T. Thammetar, English Speaking Teaching Model in Distance Education, in: Proceedings of Arab World English Journal, vol 9, 2018, pp. 418-433.

[9] L. Irawati, Critical Thinking in ELT: Theory and Practice, in: Proceedings of English Teaching Journal, vol 2, 2014.

[10] A. Lestary, An Exploration on The Use of Podcast in Speaking Class, in: Proceedings of ENLIT Journal, vol. 1, 2021, pp. 1-16.

[11] R. V. Sosas, Technology in Teaching Speaking and Its Effects to Students Learning English, in: Proceedings of Journal of Language and Linguistics Studies, vol. 17, 2021, pp. 958-970.

[12] R. A. Ningias and L. Indriani, 'EFL Students' Perspectives on Their Self-Efficacy in Speaking 
during Online Learning Process," Engine English Learning Innovation, vol. 2, 2021, no. 1, pp. 28-34.

[13] S. S. Shofatunnisa, D. Sukyadi and P. Purnawarman, "Assessing Students' Speaking Skill in Online EFL Speaking Course through Students' Self Made YouTube Videos," in Proceedings of the Thirteenth Conference on Applied Linguistics (CONAPLIN 2020) Advances in Social Science, Education and Humanities Research, Bandung, 2020. 